\title{
EL Ámbito DE LO PÚBLICO Y LA PRESENCIA DE LA IGLESIA CATÓLICA EN CHILE (1990 - 2004) (PRIMERA PARTE)
}

\author{
Jorge Precht Pizarro ${ }^{1}$
}

SUMARIO: Introducción. 1. La americanización. 2. La revolución cultural gramsciana. $2.1 \mathrm{El}$ intento de un nuevo reconocimiento jurídico de la Iglesia Católica en Cbile.

RESUMEN: Este trabajo, que forma parte de otro más extenso, parte de la base de la influencia social de la Iglesia Católica en Chile es un becho irrebatible, el cual cada cierto tiempo se producen readecuaciones entre los actores sociales que conllevan a poner en tela de juicio. Se explican en efecto los proyectos de americanización concentrado en lo personal, renunciando a tener una voz propia en el espacio público y abandonando la doctrina social de la Iglesia. Luego se aborda el modo sistemático a través del cual se ba ido produciendo una "Revolución cultural" que ba ido despojando a la Iglesia Católica en Cbile de elementos claves en el espacio público; y a propósito de la Ley 19.638, se la presenta como un intento fallido de ello.

Palabras clave: Iglesias - Iglesia Católica - Americanización - Reconocimiento jurídico - Entidades religiosas.

\section{INTRODUCCIÓN}

La influencia social de la Iglesia Católica en Chile es un hecho irrebatible. Pero cada cierto tiempo se producen readecuaciones entre los actores sociales que conllevan a poner en tela de juicio esa preponderancia manifiesta. La Iglesia ${ }^{2}$ pudo sobrellevar con éxito los empeños por desplazarla del liberalismo temprano de un Francisco Antonio Pinto; del laicismo radical-liberal del siglo XIX que culmina con las "leyes laicas", entre ellas la del matrimonio civil obligatorio en 1884; de la separación

Doctor en Derecho, Profesor titular de Derecho Constitucional, Universidad de Talca. Profesor titular de Derecho Administrativo, Pontificia Universidad Católica de Chile.

2 Recuerdo la frase de Ernesto SÁBato: "Me revienta esta forma de emplear el artículo determinado que tienen todos ellos: la Sociedad, por la Sociedad Psicoanalítica, el Partido por el Partido Comunista; la Séptima por la Séptima Sinfonía de Beethoven" (p. 20) El Túnel, Bibliotex, 1948-2000 Mediasat group. 
de la Iglesia y el Estado en 1925; del Frente Popular en 1938; de la Unidad Popular entre 1969 y 1973 y del intento de manipulación y sometimiento ideológico del régimen militar entre 1973 y 1990.

Con el advenimiento en 1990 de la democracia liberal, continuadora política del neoliberalismo económico, la Iglesia Católica en Chile enfrenta hoy por hoy un nuevo esfuerzo por desplazarla como eje constitutivo cultural de la nación chilena.

Los actores que confabulan en su contra son múltiples y la estrategia que ha adoptado la Iglesia para hacer frente a este intento se mantiene en uno de los polos tradicionales de su organización (el ultramontanismo), pero descuida otro de sus pilares organizacionales (el universalismo).

El gran organizador de la Iglesia Católica en el Chile Republicano es -terminada la fase fundacional del Arzobispo Valdivieso- el Obispo Joaquín Larraín Gandarillas y a él se debe tanto la adhesión irrestricta a la Sede Apostólica como el intelectualismo del clero, lo que permitió la existencia -dentro del tradicionalismo- de un polo pensante, uno de los pocos observatorios chilenos de la escena mundial de las ideas.

Este polo pensante y debatiente, que sirvió de contrapeso y de renovación, se ha debilitado a punto tal que la Iglesia Católica corre el riesgo de no ser ya más un referente positivo y propositivo, para convertirse en un referente en negativo y simplemente reaccionario.

El polo ultramontano salvó la ortodoxia, pero el polo universalista ha hecho de la Iglesia Católica en Chile la de una ortodoxia despierta, abierta y dialogante.

\section{LA AMERICANIZACIÓN}

Todo el catolicismo de América Latina está sometido a un proceso de americanización desde comienzos del siglo XX.

Estados Unidos ha temido siempre el catolicismo hispanista que hasta el momento ha sido irreductible, a punto tal que invade los territorios de la Unión Americana, usurpados a México, como lo evidencia el temor de Samuel P. Huntington en su libro: "¿Quiénes somos?”3.

Este proceso tiende a imponer el Credo Civil Americano es decir "un protestantismo sin Dios y un cristianismo sin Cristo" 4 .

En el caso de la Iglesia Católica se trata de es lograr "una auténtica transformación de una Iglesia Católica Apostólica y Romana en una Igle-

HUNTINGTON, Samuel P.: ¿Quiénes somos? Los desafíos a la identidad nacional estadounidense, Paidós, Barcelona, 2004.

Ob. cit. p. 133. 
sia Católica estadounidense" , la cual puede entonces formar parte -así transformada- del "pueblo elegido" al que Dios sonríe en sus empresas (Annuit Coeptus), como dice Virgilio en su Eneida y lo emplea el reverso del billete de un dólar.

O este proceso es aceptado o los católicos latinoamericanos somos considerados filisteos y reemplazados por el evangelismo pentecostal, mucho más funcional al Imperio.

Ya en 1912 Theodor Roosevelt expresó: "Creo que la asimilación de los países latinoamericanos a los Estados Unidos será difícil y larga en tanto esos países sigan siendo católicos".

Por su parte, el Cardenal Ratzinger dirá en 1985: "Siguiendo la misma línea de pensamiento, David Rockefeller recomendó en 1969, en ocasión de una conferencia dictada en Roma, suplantar allí los católicos por otros cristianos, una empresa que como sabemos está en pleno funcionamiento ${ }^{6}$.

Una parte de la intelectualidad católica chilena ha aceptado de lleno el modelo neoliberal y se ha ido sumando a proyectos de americanización de la enseñanza superior, en varios de los planteles universitarios ligados a la Iglesia.

Su manera de pensar no dista del liberalismo racionalista y desde ese punto de vista el catolicismo se ha concentrado en lo personal, renunciando a tener una voz propia en el espacio público y abandonando la doctrina social de la Iglesia.

Juan Pablo II en su exhortación apostólica postsinodal "Ecclesia in America" señala respecto de la globalización -que llega a Chile en gran medida a través de la vía americana-: "La Iglesia, aunque reconoce los valores positivos que la globalización comporta, mira con inquietud los aspectos negativos derivados de ella. ¿Y qué decir de la globalización cultural producida por la fuerza de los medios de comunicación social? Estos imponen nuevas escalas de valores por doquier, a menudo arbitrarios y en el fondo materialistas, frente a los cuales es muy difícil mantener viva la adhesión a los valores del Evangelio" (párrafo 20).

Un ejemplo de este trasvasije de valores (o antivalores) -vía americana- en el área de los medios de comunicación de la Iglesia Católica es la gestión de uno de los canales de televisión.

\footnotetext{
5 Ob. cit. p. 121. Un resumen de la postura de Huntington: "The Hispanic Challenge" apareció en Foreign Policy, Washington Mar/Apr. 2004, p. 30. (16 p.).

6 Discurso en la conferencia organizada por la Fundación Konrad Adenauer, 21 al 24 de noviembre de 1985; publicada en Contribuciones, año V, $\mathrm{N}^{\mathrm{a}} 3$ (19) julio-septiembre 1988 , CIEDLA.
} 
La contribución de Canal 13 de Televisión de la Pontificia Universidad Católica de Chile a la destrucción de la identidad católica de la nación chilena ha sido enorme ${ }^{7}$.

\section{LA REVOLUCIÓN CULTURAL GRAMSCIANA}

Sistemáticamente se ha ido produciendo bajo los gobiernos de la Concertación una "Revolución cultural" que ha ido despojando a la Iglesia Católica en Chile de elementos claves en el espacio público. Expondré en primera parte uno de esos despojos.

\subsection{El intento de un nuevo reconocimiento jurídico de la Iglesia Católica en Chile.}

Con la Ley 19.638 hubo un intento fallido de poner en cuestión el estatuto jurídico de la Iglesia Católica centrado en el ámbito civil en el artículo 547, inciso segundo del Código Civil que la reconoce como persona jurídica de derecho público, regida por leyes y estatutos especiales, situación que ha dado a la Iglesia visibilidad social y libertad apostólica $^{8}$ durante los XIX y XX.

7 Nuevamente pienso aquí en Ernesto SÁBATO: "Toda educación depende de la filosofía de la cultura que la preside; $y$ debido a esos obsecuentes imitadores de los "países avanzados" - ¿avanzados en qué? - corremos el peligro de propagar aún más la robotización. Debemos oponernos al vaciamiento de nuestra cultura, devastada por esos economicistas que solo entienden del Producto Bruto Interno -jamás una expresión tan bien lograda- que están reduciendo la educación al conocimiento de la técnica y de la informática, útiles para los negocios, pero carente de los saberes fundamentales que revelan el arte" (SĂBATO, Ernesto: Antes del fin, Memorias, Seix Barral, quinta edición, 1998, página 127).

8 El artículo 547, inciso segundo del Código Civil chileno dice lo siguiente: "Tampoco se extienden las disposiciones de este título a las corporaciones o fundaciones de derecho público, como... las iglesias, las comunidades religiosas..., estas corporaciones y fundaciones se rigen por leyes y reglamentos especiales". Esta disposición ha sido siempre entendida que se aplica a la Iglesia Católica y solo a la Iglesia Católica. En el caso Rafael Heredia y otros con Ordinario Eclesiástico de Santiago y otros, acerca de la nulidad de un testamento, la Corte Suprema estableció que dicho artículo "reconoce explícitamente a la Iglesia el carácter de corporación de derecho público, y al mismo tiempo establece que se rige por sus leyes respectivas, que constituyen el Derecho Canónico... (j) El Ordinario Eclesiástico de Santiago es una institución que forma parte de la organización de la Iglesia Católica, y en tal carácter, le alcanza la formalidad jurídica de esta y tiene capacidad para recibir asignaciones testamentarias". (C.S. 14 de marzo de 1942). La jurisprudencia ha asimismo reconocido que la extinción de una persona jurídica canónica se rige por el Derecho Canónico y no podría hacerse en sede civil (caso García con Díaz y Recoleta Franciscana, C.S. casación en la forma 25 de octubre de 1930 y casación en el fondo, 7 de noviembre de 1931, considerando $7^{\circ}$ : "Que, según el Canon 493 del Código de Derecho Canónico, una Orden Religiosa regular requiere para extinguirse una declaración expresa de la Santa Sede, que así lo establezca, y tal declaración no aparece en el proceso, por lo que debe estimarse subsistente". 
Ello no se consiguió debido a la adopción del artículo 20 de la Ley 19.638 que mantuvo respecto de la Iglesia Católica y de la Iglesia Ortodoxa Árabe, vinculada con el Patriarcado de Antioquía, el statu quo, señalando expresamente que ello no podría interpretarse como una desigualdad de trato con las demás entidades religiosas?.

Así, entonces, entre 1999 y el 2004 nada se ha alterado respecto a la personalidad jurídica de la Iglesia Católica y sus personas canónicas.

Pero respecto de los entes no católicos la Ley 19.638 creó una nueva figura jurídica llamada "personalidad jurídica religiosa" (artículo $9^{\circ}$ inciso primero); "personalidad jurídica de derecho público" (artículo 10 inciso final); "personas jurídicas religiosas" (artículo 15, inciso segundo), etc.

Curiosamente, a pesar de su denominación, el artículo 19 dice que, "La disolución de una persona jurídica constituida conforme a la ley podrá llevarse a cabo de conformidad con sus estatutos, o en cumplimiento de una sentencia judicial firme, recaída en juicio incoado a requerimiento del Consejo de Defensa del Estado, el que podrá accionar de oficio o a petición de parte, en los casos que así corresponda" 10 .

Más de 500 entidades religiosas se han acogido a la Ley 19.638.

Se ha querido dar a entender que solo hay un tipo de personalidad jurídica de derecho público para todas las iglesias, incluso la Católica.

Así en la ley reciente sobre Matrimonio Civil se dice en el artículo 20, inciso primero: "Los matrimonios celebrados ante entidades religiosas que gocen de personalidad jurídica de derecho público producirán los mismos efectos que el matrimonio civil, siempre que cumplan con los requisitos contemplados en la ley, en especial lo prescrito en este Capítulo, desde su inscripción ante un Oficial de Registro Civil".

Pero, en estricto derecho, solo se ha concedido este derecho a dos Iglesias (Católica y Ortodoxa), puesto que la personalidad jurídica especial religiosa conferida por la Ley 19.638 , no es ante el derecho, personalidad jurídica de derecho público, sino una personalidad jurídica especial de derecho privado, ${ }^{11}$ de entes de interés social.

9 Ver PRECHT, Jorge: "La Iglesia Católica y el artículo 20 de la Ley de Cultos" en Revista Chilena de Derecho, vol. 27 Nº 1, pp. 99-101 (2000), Sección Estudios. Asimismo Jorge PRECHT: "La ambigüedad legislativa como práctica parlamentaria: La Iglesia Católica y la Ley de Iglesias en su arrículo 20", Revista de Derecho U.C. del Norte, N ${ }^{\circ} 10,2003$, pp. 181 a 200.

10 Sobre mi posición véase Jorge PRECHT: Derecho Eclesiástico del Estado de Chile. Análisis bistóricos y doctrinales, Editorial Pontificia Universidad Católica de Chile, en especial capítulo quinto (páginas 199 a 226) sosteniendo el derecho constitucional a la personalidad jurídica de derecho público de toda entidad religiosa que sea reconocida por el Estado de Chile, según el artículo $19 \mathrm{~N}^{\circ} 6$ de la Constitución chilena 1980 y $10 \mathrm{~N}^{\circ} 2$ de la Constitución de 1925. Lo que la Ley 19.638 crea es un híbrido jurídico, un premio de consuelo y es inconstitucional por omisión.

11 Por eso el Profesor René Contínez habla de "Ley de Cultos: ¿Libertad religiosa o presente griego?", Revista de Derecho U. Católica del Norte, 2000, pp. 85 a 95. 
Por otra parte, si se aplica estrictamente el artículo cuarto $\mathrm{N}^{\circ} 7$ de la Ley 19.947 o nadie podría casar en sede religiosa o solo podrían hacerlo católicos y ortodoxos.

Dice el nuevo artículo 40 bis agregado a la Ley de Registro Civil: "El acta a que se refiere el artículo 20 de la Ley de Matrimonio Civil deberá estar suscrita por el ministro de culto ante quien hubieren contraído matrimonio religioso los requirentes y deberá expresar la siguiente información: $1^{\circ} \mathrm{La}$ individualización de la entidad religiosa ante la que se celebró el matrimonio, con expresa mención del numero del decreto en virtud de la (sic) cual goza de personalidad jurídica de derecho público".

Es evidente que toda la lucha de los evangélico-pentecostales fue para que no quedara supeditada su personalidad jurídica a un mero decreto del Ejecutivo ${ }^{12}$.

Y como los que tienen decreto no tienen personalidad jurídica de derecho público sino la de derecho privado del DS. 110 de 1976, Reglamento sobre concesión de personalidad jurídica de fundaciones y corporaciones los que tienen la "supuesta personalidad jurídica de derecho público" no tienen decreto, y como no es posible al Presidente de la República conceder personalidad jurídica de derecho público por decreto, ya que es materia de ley, resulta que la Ley 19.947 es inaplicable a Ias iglesias -que no sean la Católica y la Ortodoxa- en lo que se refiera al matrimonio religioso con efectos civiles.

Pero a su vez, en estas Iglesias, Católica y Ortodoxa, se aplica la siguiente norma: "En el caso de las entidades religiosas reconocidas por el artículo 20 de la Ley 19.638; deberán citar esta norma jurídica".

Ahora bien, la Iglesia Católica en Chile no fue reconocida en 1999 por el Estado de Chile ni tampoco lo fue la Iglesia Ortodoxa por el artículo 20 de la Ley 19.638.

Dicho artículo solo constata que algunas Iglesias tienen personalidad jurídica a la fecha de la publicación de la Ley 19.638, y que algunas lo tienen de derecho público.

12. El Consejo de Defensa Del Estado ha sostenido -al igual que la jurisprudencia y la Comisión de Estudios de la Nueva Constitución- la doctrina correcta:..." la personalidad jurídica de derecho público no se obtiene sino en virtud de un precepto constitucional o legal que la otorgue. La de los entes que gozan de ella se da por supuesta en las distintas normas jurídicas, tratados y convenios internacionales y documentos oficiales que las mencionan, aceptándose que la personería de quienes los representan emana de resoluciones o acreditaciones otorgados por sus propios órganos. Tal es el caso, por ejemplo, de los Estados, de las distintas naciones y de algunas instituciones que, por su tradición histórica y su prestigio, se reconocen universalmente, como la Iglesia Católica Apostólica y Romana y la Cruz Roja Internacional entre otras... No cabe duda a este Consejo que la Iglesia Católica Apostólica y Romana... goza de una personalidad jurídica de derecho público que no se le ba dado por ninguna autoridad civil y que no puede perderla por disposición de esta". Informe $\mathrm{N}^{\circ} 192$ de 25 de mayo de 1977). 
Así entonces, el numeral $1^{\circ}$ del artículo cuarto, alinea 7 de la nueva Ley de Matrimonio Civil (Ley 19.947) es un disparate ${ }^{13}$.

La Ley 19.638, por otra parte, se encuentra en un zapato chino. El artículo $9^{\circ}$ de esta ley estableció la facultad de crear personas jurídicas en el seno de las entidades religiosas no católicas, sin ninguna restricción, en un sistema amplísimo de reconocimiento de entidades religiosas.

Es decir, el ius statuendi del derecho canónico fue catapultado para toda entidad religiosa reconocida conforme a la Ley 19.638 en un sistema de simple inscripción de estatutos que señala además en su artículo $4^{\circ}$ : "Para efectos de esta ley, se entiende por iglesias, confesiones o insticuciones religiosas a las entidades integradas por personas naturales que profesan una determinada fe".

Sobre estas personalidades religiosas derivadas, el Ministerio de Justicia no tiene atribución alguna, así como no las tiene sobre las normas según las cuales son ellas creadas ya que el mencionado artículo $9^{\circ}$ dice: "Las asociaciones, corporaciones, fundaciones y otros organismos creados por una iglesia, confesión o institución religiosa que, conforme a sus normas jurídicas propias gocen de personalidad jurídica religiosa, son reconocidos como tales. Acreditará su existencia la autoridad religiosa que los haya erigido o instituido".

"Las entidades religiosas, así como las personas jurídicas que ellas constituyen en conformidad a esta ley, no podrán tener fines de lucro".

A las más de 500 entidades religiosas reconocidas hay que agregar este factor multiplicador de "iglesias que dan crías".

Si el Estado de Chile pretende hoy poner coto a esta génesis eclesial se va a producir que los entes afectados reclamarán de esta restricción como un atentado a la libertad religiosa.

Será difícil defender como "discriminación no arbitraria” el que las Iglesias Católica y Ortodoxa apliquen sus cánones (régimen jurídico propio) sin restricción alguna y que los entes no católicos estén -por el contrario-sometidos al tutelaje del Ministerio de Justicia ${ }^{14}$.

13 Es otra paradoja que se podría incluir encre las que enumera el Profesor Hernán CORRAL: "Una ley de paradojas. Comentario a la Nueva Ley de Matrimonio Civil". Universidad de los Andes. Documento de Trabajo $\mathrm{N}^{\circ} 59$ (Trabajo enviado para ser publicado en el $\mathrm{N}^{\circ} 2$ de la Revista Chilena de Derecho Privado, que aparece en el segundo semestre de 2004). Tal es la tesis ya adelantada por el profesor Alberto LYON en su libro Personas Juridicas, Editorial Pontificia Universidad Católica de Chile (marzo 2003): "La expresión del artículo 20 de la Ley 19.638 ("sin que ello sea causa de trato desigual entre dichas entidades y las que se constituyan en conformidad a esta ley"), puede resultar ambigua, pues es de suyo desigual que unas confesiones no necesiten -para obtener personalidad jurídica- la intervención del Estado porque gozan de una personalidad de derecho público y otras sí. Sin embargo, conforme a lo dispuesto en el artículo 9 de la misma ley, se establece plenamence que "se reconoce que las asociaciones, corporaciones, fundaciones y otros organismos" creados por una iglesia, confesión o institución religiosa que conforme a sus normas jurídicas propias gocen de personalidad jurídica son reconocidas como tales. Acredita su existencia -dice la ley-la autoridad religiosa que los haya erigido o institui- 
Y si para evitar aquello el Estado extiende su control a los entes canónicos de la Iglesia Católica viola el marco constitucional, así como el propio artículo 20 de la Ley 19.638 que reconoció no solo las personalidades canónicas existentes a 1999 y las normas que las regularan en ese momento, sino que sine die el régimen jurídico que les propio, ${ }^{15}$ es decir continuar con el derecho de crear personas canónicas en su seno.

Cualquier nuevo esfuerzo de equiparar -nivelando hacia abajo- a las entidades religiosas, forma parte de este intento de "reconocer, desconociendo", que algunos sectores están aplicando a la Iglesia Católica en Chile a partir de 1990.

En efecto, es de suponer que no querrá el Estado de Chile retrotraer las cosas a agosto de 1925 y ejercer derechos de Patronato sobre los entes derivados de la Iglesia Católica y de la Iglesia Ortodoxa ${ }^{16}$ y resucitar el "exequátur" o "pase regio" sobre las normas canónicas de erección de estas personas jurídicas canónicas, convirtiéndose el Ministerio de Justicia en Ministerio de Culto, asumiendo labores que otrora ejerciera el Consejo de Estado.

La Iglesia Católica goza en Chile de un sistema jurídico privilegiado, fruto de acuerdos celebrados entre el Estado de Chile y dicha Iglesia.

Esto no debe ser entendido ni como contrario a la igualdad ante la ley ni siquiera a la llamada "igualdad de trato", pues el derecho eclesiástico del Estado comparado muestra que en todos los pactos internacionales de derechos humanos existe, en esta materia, un margen de libre apreciación de los Estados, aun en el caso de haberse comprometido a crear las condiciones necesarias para evitar la discriminación por motivos religiosos y a impedir que ella tenga a lugar, también en el ámbito privado $^{17}$.

do". Esto significa en la práctica que no se produce trato desigual alguno, desde el momento que las iglesias que no gocen de personalidad juridica de derecho público pueden obtener personalidad jurídica sin intervención del Estado" ( $p .79)$.

15 Recordemos que la Pastoral Colectiva de los OBispos De Chile el 20 de septiembre de 1925 dijo: "...Pasando a lo temporal la nueva Constitución no innova en el reconocimiento ni en la organización de la personalidad jurídica de que gozaba la Iglesia Católica bajo el imperio de la constitución de 1833 y de las leyes existentes en el momento de su reforma" y tanto es así que el 20 de octubre de 1925 -el mismo día de entrada en vigencia de la Constitución- la Iglesia Católica procedió a la erección de numerosas diócesis, sin intervención alguna del Estado y conforme solo a las normas canónicas. La Ley 17.725 concede personalidad jurídica a la Arquidiócesis Católica Apostólica Ortodoxa de Chile y en su artículo único dice que se regirá por sus Estatutos y por las normas canónicas y eclesiásticas aplicables a dicha institución religiosa.

17 Es lo que sostiene David GARCÍA PARDO en La proteción internacional de la libertad religiosa, Servicio de Publicaciones. Universidad Complutense, Facultad de Derecho, Madrid, 2000, página 49, y luego añadirá en la página 81 que ni el sistema de iglesias de Estado ni los regímenes concordatarios, etc. da a entender que dichas situaciones sean discriminatorias y concluye: "Lo mismo cabría decir en relación a aspectos concretos de la normativa de los distintos estados que dan origen a situaciones de diversidad de trato que redundan de alguna manera en la libertad religiosa del individuo - enseñanza religiosa en la escuela 
El intento de uniformizar el estatuto jurídico de la Iglesia Católica en Chile asimilándolas al de las de las iglesias minoritarias responde a razones ideológicas, pero no se sostiene ante el derecho.

$\mathrm{Y}$ es lamentable que las iglesias no católicas reconocidas no reciban en la Ley 19.638 lo que desde 1925 les corresponde: una verdadera personalidad jurídica de derecho público ${ }^{18}$ con todas sus posibilidades.

pública o asistencia religiosa, de las cuales se benefician los miembros de una o varias confesiones religiosas por citar solo dos ejemplos. Dicho en palabras de MARGIOTA-BroGLIO. El artículo 14 del Convenio Europeo "garantisce contro una aplicaciones discriminante, non contro diversitá di tratamento che non si risolva in tal senso" (MARGIOTTA-BroGLIO, F; "Religione e Stato in alcuni sistemi costituzionali atipici. Il caso della Convenzione Europea del 1950", en MARTínez TORRON, J: La libertad religiosa... cit. páginas 299-310). Véase JORGe PrECht PiZARro: "La asistencia religiosa a las Fuerzas Armadas y el derecho comparado", Revista Chilena de Derecho, XXX (2003) pp. 55-63. (b) "En consecuencia y resolviendo las dificultades que se advierten en la doctrina para categorizar a las. Iglesias, Confesiones e Instituciones Religiosas, la Ley $\mathrm{N}^{\circ} 19.638$ ha venido a expresar lo que siempre ha sido evidente: Que no existe una sola categoría y, por ende, un estatuto jurídico único, para todas y cada una de aquellas entidades, sino que existen en nuestro sistema jurídico diversas categorías y múltiples estatutos que las rigen, en cada uno de los asuntos donde es menester que exista regulación" (artículo citado, página 249). Véase Orrego Sánchez, Cristóbal y Saldaña Serrano, Javier; "Igualdad Religiosa e Igualitarismo jurídico" en Revista Chilena de Derecho, XXVII, Santiago, Facultad de Derecho, Universidad Carólica de Chile, 2000, páginas 81-92. Sobre mi interpretación del artículo $19 \mathrm{~N}^{\circ} 6$ de la Constitución, véase Jorge Precht Pizarro: "La libertad religiosa en la Constitución chilena de 1980" en A.A.V.V. La Constitución de 1980. 20 años de vigencia, Universidad Finis Térrae 2000, páginas 225 a 248.

Se ha sumado últimamente a la posición favorable a la personalidad jurídica de derecho público de todos los entes religiosos que sean reconocidos como tales por el Estado de Chile Miguel Angel FernÁNDEZ en "Régimen Constitucional de las Iglesias" en A.A.V.V. Estudios Constitucionales. Revista del Centro de Estudios Constitucionales. Universidad de Talca, Santiago, Chile, 2003, páginas 229 a 254. Fernández enfatiza dos aspectos muy importantes:

a) Que la personalidad jurídica de derecho público hace que la intervención del Estado en la Ley 19.638 es meramente cerrificatoria y no constitutiva (citando la doctrina de "Iglesia de Dios en Chile con Ministerio de Justicia", considerandos $3^{\circ}$ y $4^{\circ}$ de la sentencia pronunciada por la Corte de Apelaciones de Concepción el 14 de junio de 2001 (R.D.J. XCVIII, Revista de Derecho y Jurisprudencia N 2 (abril, junio 2001), confirmada por la Corte Suprema el 6 de agosto de 2001.

b) "En consecuencia y resolviendo las dificultades que se advierten en la doctrina para categorizar a las Iglesias, Confesiones e Instituciones Religiosas, la Ley $\mathrm{N}^{\circ} 19.638$ ha venido a expresar lo que siempre ha sido evidente: Que no existe una sola categoría y, por ende, un estatuto jurídico único, para todas y cada una de aquellas entidades, sino que existen en nuestro sistema jurídico diversas categorías y múltiples estaturos que las rígen, en cada uno de los asuntos donde es menester que exista regulación" (arrículo citado, página 249). Véase OrRego SánChez, Cristóbal y Saldaña Serrano, Javier: "Igualdad Religiosa e Igualitarismo jurídico" en Revista Chilena de Derecbo XXVII, Santiago, Facultad de Derecho, Universidad Católica de Chile, 2000, páginas 81-92.

Sobre mi interpretación del arrículo $19 \mathrm{~N}^{\circ} 6$ de la Constitución, véase Jorge PRECHT PIZARro: "La libertad religiosa en la Constitución chilena de 1980" en A.A.V.v. La Constitución de 1980. 20 años de vigencia, Universidad Finis Térrae 2000, páginas 225 a 248 . 
Pero es igualmente lamentable que se quisiera restringir el ius statuendi ya reconocido en el artículo 9 de la Ley 19.638 otorgando un Patronato sobre entidades religiosas no católicas.

Ya en el año 2000 yo escribí sobre este artículo 9: "El derecho de regirse por su propio ordenamiento y por el régimen jurídico que le es propio a cada entidad religiosa es inherente a la existencia misma de cada iglesia, confesión o institución religiosa.

Su puesta en relieve es uno de los grandes logros del artículo 20 de la Ley de Iglesias $\mathrm{N}^{\circ} 19.638$ y es por ello que rechazo con energía una "interpretación reduccionista" que pretendiera limitar tal derecho solo a la Iglesia Católica Romana y a la Arquidiócesis Ortodoxa y privar del ius statuendi a las nuevas comunidades religiosas que usen la Ley 19.638, es especial su artículo noveno".

"En efecto, no hay peor defensa para los justos derechos de los católicos y ortodoxos que el dejar fuera de poder gozar de similares posibilidades a las entidades religiosas no católicas".

Y escribí algo que está muy cerca de intentarse: "Ello llevará tarde o temprano al Estado, que siempre ha sido el principal enemigo de la libertad religiosa, a someter "al derecho común" también este bien incorporal que asegura algo tan esencial a toda vivencia religiosa, esto es, el vivir en plenitud la especificidad de su carisma"19 (continuará).

\section{BIBLIOGRAFÍA CitADA}

- Cortínez, René: "Ley de Cultos: ¿Libertad religiosa o presente griego?", Revista de Derecho, Universidad Católica del Norte, sede Coquimbo, 2000

- Fernández, Miguel Angel: "Régimen Constitucional de las Iglesias", en Estudios Constitucionales, Revista del Centro de Estudios Constitucionales, Universidad de Talca, Santiago, Chile, 2003.

- García PARDO, David: La protección internacional de la libertad religiosa, Servicio de Publicaciones. Universidad Complutense, Facultad de Derecho, Madrid, 2000.

- Huntington, Samuel P.: ¿Quiénes somos? Los desafíos a la identidad nacional estadounidense, Paidós, Barcelona, 2004.

- Huntington: "The Hispanic Challenge" apareció en Foreign Policy, Washington Mar/Apr. 2004.

- LyON, Alberto: Personas Jurídicas, Editorial Pontificia Universidad Católica de Chile, 2003.

19 Artículo citado en AA.Vv.: La Constitución de 1980. 
- Margiotta-Broglio, F: "Religione e Stato in alcuni sistemi costituzionali atipici. Il caso della Convenzione Europea del 1950".

- OrRego SÁnchez, Cristóbal y Saldaña Serrano, Javier: "Igualdad Religiosa e Igualitarismo jurídico" en Revista Chilena de Derecho, XXVII, Santiago, Facultad de Derecho, Universidad Católica de Chile, 2000.

- PReCHT, Jorge: "La Iglesia Católica y el artículo 20 de la Ley de Cultos" en Revista Cbilena de Derecho, vol. 27 N ${ }^{\circ} 1,2000$.

- Precht Pizarro, Jorge: "La ambigüedad legislativa como práctica parlamentaria: La Iglesia Católica y la Ley de Iglesias en su artículo 20", Revista de Derecho, Universidad Católica del Norte, sede Coquimbo, $\mathrm{N}^{\circ} 10,2003$

- Precht Pizarro, Jorge: Derecho Eclesiástico del Estado de Chile. Análisis históricos y doctrinales, Editorial Pontificia Universidad Católica de Chile, 2001.

- Precht Pizarro, Jorge: "La asistencia religiosa a las Fuerzas Armadas y el derecho comparado", Revista Chilena de Derecho, XXX, 2003.

- Precht Pizarro, Jorge: "La libertad religiosa en la Constitución chilena de 1980" en A.A.V.V. La Constitución de 1980. 20 años de vigencia, Universidad Finis Térrae, 2000.

- S.S. Juan Pablo II: "Ecclesia in America", discurso, publicado en Contribuciones, año V, $\mathrm{N}^{\circ} 3$ (19) julio-septiembre 1988, CIEDLA.

- SÁBATo, Ernesto: El Túnel, Bibliotex, 1948 - 2000 Mediasat group.

- Sábato, Ernesto: Antes del fin, Memorias, Seix Barral, quinta edición, 1998. 